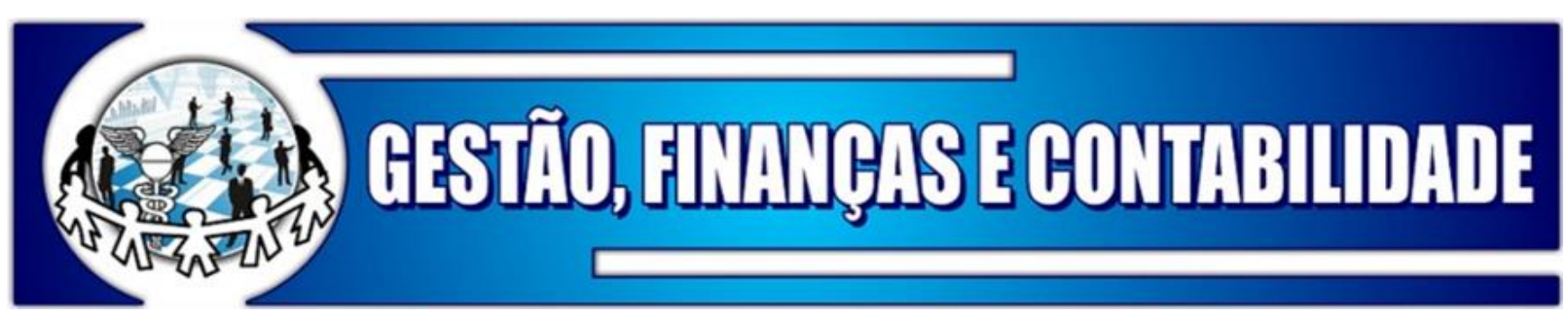

\title{
RISCO IDIOSSINCRÁTICO DETERMINADO POR CARACTERÍSTICAS SETORIAIS E DE GOVERNANÇA
}

\section{IDIOSYNCRATIC RISK DETERMINED BY SECTOR AND GOVERNANCE CHARACTERISTICS}

\section{RIESGO IDIOSINCRATICO DETERMINADO POR CARACTERÍSTICAS SECTORIALES Y DE GOBERNANZA}

\begin{abstract}
Alyne Cecilia Serpa Ganz
http://orcid.org/0000-0002-7192-6033

Doutoranda do Programa de Pós-graduação em Métodos Numéricos em Engenharia pela Universidade Federal do Paraná (PPGMNE/UFPR) Mestre em Ciências Contábeis pela Universidade Regional de Blumenau (PPGCC/FURB) E-mail: alyneserpa@hotmail.com

Luana Sara Bizatto https://orcid.org/0000-0002-2259-989X Mestre em Ciências Contábeis pela Universidade Regional de Blumenau (PPGCC/FURB) E-mail:luanasarabizatto@hotmail.com

Adriana Kroenke https://orcid.org/0000-0001-6625-3017 Professora do Programa de Pós-Graduação em Ciências Contábeis e Administração da Universidade Regional de Blumenau (PPGCC/FURB) Doutora em Métodos Numéricos em Engenharia pela Universidade Federal do Paraná (PPGMNE/UFPR)

E-mail: akroenke@ furb.br
\end{abstract}

\section{RESUMO}

O risco idiossincrático tem sido alvo de diversas investigações que objetivam entender e explicar este risco. Diversas vertentes de explicação para este risco são sugeridas pela literatura, dentre estas estão a governança corporativa e o setor econômico. Deste modo o presente estudo tem por objetivo analisar o risco idiossincrático nos diferentes setores econômicos e níveis de governança. A amostra é composta por 356 empresas, no período de 2011 a 2015, sendo que para alcance dos resultados são utilizados os modelos de 3 e 5 fatores de Fama e French $(1993,2015)$, teste de médias e regressão linear múltipla. Os resultados indicam que o setor de tecnologia e telecomunicação possui o maior risco idiossincrático, e Petróleo, Gás e Biocombustível apresenta o menor valor para o mesmo risco. Além desses a governança é encontrada para diminuir o risco idiossincrático. A pesquisa contribui para os 
usuários externos da informação contábil, ao identificar quais características setoriais e de governança impactam neste risco em cenário brasileiro, encontrando que alguns setores e o nível de governança corporativa discriminam de diferentes formas no risco idiossincrático.

Palavras-chave: Risco Idiossincrático; Setores Econômicos; Níveis de Governança.

\begin{abstract}
The idiosyncratic risk has been the object of several investigations that aim to understand and explain this risk. Several explanatory factors for this risk are suggested in the literature, among them are corporate governance and the economic sector. Thus, the present study aims to analyze the idiosyncratic risk in the different economic sectors and levels of governance. The sample is composed of 356 companies, in the period from 2011 to 2015, and to achieve the results, the models of 3 and 5 factors of Fama and French (1993, 2015), test of means and multiple linear regression are used. The results indicate that the technology and telecommunication sector has the highest idiosyncratic risk, and Petroleum, Gas and Biofuel presents the lowest value for the same risk. In addition, governance is found to reduce idiosyncratic risk. The research contributes to external users of accounting information, by identifying which sectoral and governance characteristics impact on this risk in a Brazilian scenario, finding that some sectors and the level of corporate governance discriminate in different ways in idiosyncratic risk.
\end{abstract}

Keywords: Idiosyncratic Risk; Economic Sectors; Levels of Governance.

\title{
RESUMEN
}

El riesgo idiosincrático ha sido objeto de diversas investigaciones que objetivan entender y explicar este riesgo. Diversas vertientes de explicación para este riesgo son sugeridas por la literatura, entre ellas están la gobernanza corporativa y el sector económico. De este modo el presente estudio tiene por objetivo analizar el riesgo idiosincrático en los diferentes sectores económicos y niveles de gobernanza. La muestra está compuesta por 356 empresas, en el período de 2011 a 2015, y para lograr los resultados, se utilizan los modelos de 3 y 5 factores de Fama y French $(1993,2015)$, prueba de medias y regresión lineal múltiple.Los resultados indican que el sector de tecnología y telecomunicación posee el mayor riesgo idiosincrático, y Petróleo, Gas y Biocombustible presenta el menor valor para el mismo riesgo. Además de esta gobernanza se encuentra para disminuir el riesgo idiosincrático. La investigación contribuye a los usuarios externos de la información contable, al identificar qué características sectoriales y de gobernanza influyen en este riesgo en el escenario brasileño, encontrando que algunos sectores y el nivel de gobierno corporativo discriminan de diferentes formas en el riesgo idiosincrático.

Palabras clave: Riesgo idiosincrático; Sectores Económicos; Niveles de Gobernanza.

\section{INTRODUÇÃO}

Uma das temáticas mais investigada na área financeira é a precificação de ativos e os riscos incumbido a esse. A discussão sobre a precificação dos ativos financeiros teve início com o trabalho de Markowitz (1952) sobre a diversificação de portfólios, no qual o autor relacionou o risco ao retorno das ações. Sharpe (1964), Lintner (1965) e Mossin (1966) aperfeiçoaram o modelo de Markowitz (1952) e desenvolveram o amplamente difundido CAPM (Capital Asset Princing Model) que relaciona o retorno esperado das ações ao risco sistêmico e idiossincrático.

Deste modo, tem-se dois riscos relacionados na explicação do retorno das ações, o risco sistêmico e o idiossincrático. O risco sistêmico é o risco não-diversificável, relacionado a 
eventos pertinentes á todo o mercado (MENDONÇA et al., 2012), que sugere a tendência de toda a negociação variante. Já o risco idiossincrático é o risco específico à cada empresa, ou seja, é a parcela de risco incumbido a uma ação ou ativo em particular, podendo ser anulado em portfólios totalmente diversificados (GALDI; SECURATO, 2007; FU, 2009; MENDONÇA et al., 2012).

$\mathrm{Fu}$ (2009) afirma, porém, que são realmente escassos os investidores que possuem um portfólio totalmente diversificado, logo alguma parcela de risco idiossincrático estará estimada nas suas ações. Por este risco ser a volatilidade das ações acima ou abaixo do retorno do mercado, este é alvo de estudo pela carência de fatores que o expliquem (ROLL, 1988).

Levando em consideração a particularidade do risco idiossincrático e a falta de conhecimento sobre fatores que o expliquem o presente estudo visa relacionar a estimação deste risco com os dez setores econômicos (Bens Industriais, Consumo Cíclico, Consumo não Cíclico, Financeiro e Outros, Materiais Básicos, Petróleo. Gás e Biocombustíveis, Saúde, Tecnologia da Informação, Telecomunicações e Utilidade Pública) de acordo com a B3, e identificar se estes riscos são discriminados de acordo com o setor econômico.

Os setores brasileiros têm apresentado sinais de solidez econômica (RIGHI; SCHLENDER; CERETTA, 2014), o que estimula a averiguação destes com fatores voláteis. Os autores supracitados afirmam também que o conhecimento do panorama econômico de setores de mercado de ações deve ser investigado uma vez que influencia na tomada de decisão. O estudo de Silva, Paulo e Silva (2016) analisam como as caraterísticas dos setores da economia afetam os números contábeis, encontrando uma relação entre as características dos setores e o conservadorismo. O presente estudo difere identificando se as mesmas características setoriais influenciam na intensidade do risco idiossincrático.

Outra característica pertinente as classificações do mercado de capitais brasileiros são os níveis diferenciados de governança corporativa. A Bolsa de Valores de São Paulo com intuito de criar benefícios para o aumento da negociação de investimentos, determinou em 2000 novos segmentos especiais de classificação na Bolsa (Nível 1, Nível 2 e Novo Mercado), com regimento austero sobre governança (TONANI; SILVA, 2014). De acordo com a B3 (2016) a origem dos níveis criados fora para melhorar a avaliação, estimular o interesse e a valorização das organizações aderentes, voluntariamente, a algum dos níveis propostos (TONANI; SILVA, 2014; BESSARIA et al., 2015). Assim ainda é conveniente que menores riscos estejam incumbidos à essas empresas melhores avaliadas.

Avaliando o risco idiossincrático como a volatilidade da ação não respondida por fatores mercadológicos, e ligação do mesmo com a governança, tem-se o estudo e Rogers, Machado Filho e Securato (2008) que usaram o modelo de série temporal $(\mathrm{GARCH})$ para mensurar o risco idiossincrático e relaciona-lo com a governança corporativa, concluindo que empresas que não seguem diretrizes de governança tem maior volatilidade e maior assimetria de informação, enquanto as empresas com nível mais elevado de governança tendem a reduzir a volatilidade. Sendo assim, o presente trabalho se diferencia dos demais e visa preencher a lacuna de pesquisa quanto a discriminação da governança corporativa, nas formas dos níveis de governança da B3, e de diferenças setoriais para com o risco idiossincrático. Isto possibilitará ao investidor ter um maior conhecimento sobre quais setores e níveis de governança estão incumbidos os maiores riscos específicos, bem como os que estão mais alinhados e são mais influenciados pelos aspectos mercadológicos em geral.

No contexto apresentado da volatilidade não explicável do retorno das ações ao nível do risco idiossincrático, e o que pode estar influenciando ou explicando parte deste risco, surge a seguinte questão que norteou o presente trabalho: Quais setores econômicos e níveis de governança discriminam de forma diferente dos demais o risco idiossincrático? E ainda para 
responder à pergunta de pesquisa apresentada tem se como objetivo analisar o risco idiossincrático nos diferentes setores econômicos e níveis de governança.

O presente estudo se justifica de forma principal pela afirmativa de Costa, Mazzeu e Costa Jr. (2016) de que estudos que investiguem a influência dos diferentes tipos de ações, setores ou níveis de governança no risco idiossincrático é importante e relevante para a literatura sobre o tema. Bali et al., (2008) ainda afirma a importância do estudo deste tipo de risco uma vez que esse se faz relevante na tomada de decisões de investimento. Neste sentido diversos estudos têm se empenhado para explicar características deste risco em especifico.

Silva, Reis e Amâncio (2014) ainda afirmam que os setores aos quais atuam as empresas as levam a diferentes posicionamentos. O que implica na relevância de estudos que abordem todos esses setores e analisem se esses apresentam características tão diferenciadas entre si. Mencionados esses, o presente estudo visa contribuir no entendimento do risco idiossincrático entre diferentes níveis de governança e diferentes setores econômicos, visto sua importância no investimento. E ainda contribuir ao ampliar e consolidar características sobre o risco idiossincrático.

\section{RISCO IDIOSSINCRÁTICO, DIVISÕES SETORIAIS E NÍVEIS DE GOVERNANÇA CORPORATIVA}

A literatura vem estudando o risco idiossincrático vastamente nos períodos mais recentes, com a pretensão de encontrar fatores que expliquem este risco e verifiquem a sua associação com o retorno das ações, isto por ser considerado uma das mais importantes anomalias presente no mercado de capitais (VIDAL-GARCIA; VIDAL; NGUYEN, 2016; LEE; LI, 2016). A dificuldade em encontrar por vezes resultados invariantes entre diferentes estudos que procuram conhecer e compreender o risco idiossincrático, provem da causa da utilização de diferentes amostras, períodos, países e métodos.

O risco idiossincrático segundo Alexandre, Lima e Canuto (2008) é um dos riscos que juntamente com o risco de mercado local e sistêmico são mais relevantes para instituição financeira. $\mathrm{O}$ estudo sobre a relação entre risco e retorno se desenvolveu excepcionalmente após o desenvolvimento do modelo de precificação de ativos financeiros por Sharpe (1964) e Lintner (1965) que relacionou pela primeira vez o risco ao retorno, aprimorando a ideia inicial de Markowitz (1952) sobre a diversificação do portfólio. A partir deste modelo original diversos outros modelos foram desenvolvidos e aperfeiçoados com a intenção de mensurar mais precisamente o retorno das ações bem como os riscos incumbidos a esses.

Há dois principais riscos incorporados nos modelos supracitados, o primeiro referente ao risco sistemático que abrange os títulos e negociações da bolsa, também interpretado como o risco da macroeconomia, e que tem impacto direto na valorização e desvalorização das ações, sendo impossível de ser eliminado; e o segundo que diz respeito ao risco não-sistemático ou idiossincrático, inerente as particularidades de casa ativo e de cada empresa, sendo diversificável por ser possível de anulação em carteiras totalmente diversificadas (MONTE et al., 2010). Este risco idiossincrático reflete informações especificas da empresa que é volátil por origem (ALEXANDRE et al., 2008; FU, 2009).

Essa natureza volátil característica deste tipo de risco ocorre por conta de inúmeros fatores como a divulgação de informação dos lucros, a periodicidade dessa informação, variações sazonais, concorrência, rentabilidade da empresa entre outros fatores específicos e particulares incorridos no íntimo da organização (FU, 2009). Este risco por ser tão intrínseco de decisões e ações corporativas de cada empresa, é tomado por vezes como indeterminado, visto que sua previsão ou mensuração é por vezes rasa. 
Ghunmia, Bino e Tayeh (2015) afirmam que no contexto contemporâneo algumas variáveis das quais tem relação com o risco especifico das empresas já foram identificadas e comprovadas suas influências. Porém a literatura ainda não foi capaz de explicar por completo este risco (RUBIN; SMITH, 2011). Tal contexto está incentivando diversos estudos, estes que tentam cada vez mais achar características das empresas que expliquem o valor assumido de tal risco.

Um dos fatores possíveis de caracterização deste risco são os setores de atividade econômica, em quais as empresas listadas na Bolsa de Valores de São Paulo são separadas. A classificação é realizada considerando, essencialmente, os tipos e os usos dos produtos e serviços desenvolvidos pelas empresas (B3, 2016). A Bolsa organiza as empresas em tais setores com determinados propósitos como: "fornecer uma identificação mais objetiva dos setores de atuação das empresas, já a partir do primeiro nível da estrutura; permitir uma visão sobre empresas que, embora com atividades diferentes, atuem em estágios similares da cadeia produtiva ou com produtos/serviços relacionados e tendam a responder de forma semelhante às condições econômicas; facilitar a localização dos setores de atuação das empresas negociadas; e aproximar-se de critérios utilizados pelo mercado financeiro nacional e internacional".

Empresas que operam em mais de um setor de atividade econômica são classificadas com base na composição de sua receita, sendo essa classificada no setor que contabiliza a maior parte desta. O mercado ainda classifica como holding diversificada as empresas que atuam em diversos setores e não é possível classificar um como seu principal gerador de renda.

Segundo Assaf Neto (2007) as decisões financeiras racionais são em suma feitas com base na relação entre o risco que irá se submeter e o retorno que se pretende receber, visto que diferentes setores tendem a ter diferentes retornos e características, pressupõe-se a ocorrência de diferentes riscos. Os setores de atividades econômicos classificados pela Bovespa são dez: Bens Industriais, Consumo Cíclico, Consumo não Cíclico, Financeiro e Outros, Materiais Básicos, Petróleo. Gás e Biocombustíveis, Saúde, Tecnologia da Informação, Telecomunicações e Utilidade Pública, estes para serem melhores comparáveis com os setores de outros países.

Os setores denominados acima, classificados pelo mercado de capitais brasileiro, tem apresentado certa solidez econômica (RIGHI et al., 2014) e com o risco idiossincrático é referente à uma volatilidade não explicável incumbida nos retornos das ações, se faz relevante a investigação de tal solidez com tal anomalia volátil. Como os setores possuem características diferentes e por tal é separado, estima-se que aleatoriamente diferentes setores podem agrupar características similares quanto ao risco idiossincrático de suas empresas. Assim como Silva et al. (2016) analisaram se essas características setoriais influenciariam no grau de conservadorismo das empresas, e o presente estudo pretende relacionar de forma semelhante as características dos diferentes setores, porém neste, relacionando com o risco idiossincrático das organizações.

Leary e Michael (2010) afirmam que outra variável que influencia a estrutura de capital das empresas e consequentemente das ações e riscos são as práticas de boa governança, por reduzir a assimetria das informações e as idealizações distintas por partes dos gestores. Como se vem desenvolvendo as decisões com base na relação risco e retorno tende a ter como referência as informações que se possui em determinado período de previsão. O nível de informação recebida e a confiabilidade de tais informações estão também relacionadas com a transparência de divulgação da empresa, e um fato que condiz com tal aspecto e a Governança Corporativa, que objetiva proporcionar um mais alto nível de transparência na divulgação de resultados econômicos e financeiros, o que auxilia na redução dos riscos na tomada de decisão (MONTE et al., 2010). 
A governança corporativa sendo tida como práticas que enfatizam a transparência nas divulgações de informações e permitindo aos supridores do capital assegurar os retornos de seus investimentos (MONTE et al., 2010) a B3 (Brasil, Bolsa, Balcão) em 2000 deliberou a criação dos níveis de governança corporativa para tal bolsa, com intuito de desenvolver o mercado de capitais, separando de forma apropriada os diversos perfis de empresas (B3, 2016).

Os níveis criados pela gestão da Bolsa de Valores de São Paulo fora os níveis de 1 e 2 e o Novo Mercado, os quais tens as empresas classificadas nestes de acordo com determinados critérios. Em ordem crescente de requisitos para categorização tem-se o Nível 1, Nível 2 e Novo Mercado, sendo o Nível 1 com menores grais de classificação e o Novo Mercado com maior grau de requisitos, atendendo tanto aos critérios dos níveis anteriores quanto aos próprios de sua classificação. Os níveis de governança "prezam por rígidas regras de governança corporativa. Essas regras vão além das obrigações que as companhias têm perante a Lei das Sociedades por Ações (Lei das S.As.) e têm como objetivo melhorar a avaliação daquelas que decidem aderir, voluntariamente, a um desses segmentos de listagem" (B3, 2016).

Para Monte et al. (2010) a adesão das empresas aos diferentes níveis de governança da bolsa possibilita maior destaque as ações despendidas por essas na melhoria do relacionamento com os investidores, elevando assim o seu potencial de valorização dos seus ativos no mercado e reduzindo em parte o risco quanto aos negócios. As classificações de governança possibilitam as organizações a valorização dos seus esforços em suas atividades em diminuir a assimetria de informação contida nos seus relatórios que são disponibilizados para os usuários externos, suas preocupações para com a gestão da empresa e suas ações para ter vantagem em mercados tão competitivos.

Tal modelagem incorporada pela Bolsa de São Paulo já foi usada em outros países e desenvolveu bom resultado, sendo este interpretado por vezes como um selo de qualidade ao qual as companhias ganham ao terem ações que as expliquem quanto a governança da empresa. Ainda conforme Silva, Araújo e Monte (2015) a adesão das empresas aos níveis de governança corporativa, geram diversos bônus às organizações como um desempenho de maior nível, um maior valor de mercado, um acréscimo na liquidez e impacto direto na estrutura de capital. Monte et al. (2010) encontraram em seu estudo que as empresas listadas no Novo mercado apresentaram menor volatilidade dos que as empresas dos demais níveis de governança. Silva et al. (2015) afirmam também que os níveis 1 e 2 de governança corporativa da bolsa não devem possuir grandes diferenças. Tais diferenças entre os níveis de governança é o que discrimina as empresas pertencentes a cada nível e, portanto, são os aspectos que podem influenciar o risco especifico das empresas que compõe esses grupos.

Ha diversos estudos recentes que afirmam uma relação entre a governança corporativa e o risco idiossincrático (DURNEV; MORCKE; YEUNG, 2004; FERREIRA; LAUX, 2007;ROGERS; RIBEIRO; SOUZA, 2007; MATUCHESKI; CLEMENTE; SANDRINI, 2009; NGUYEN, 2011; CAZZARI; FÁVERO; TAKAMATSU, 2015; GHUNMI et al., 2015), esses por meio de alguma classificação quanto ao nível de governança, por meio da estrutura de propriedade, conselho de administração, entre outros diversos aspectos da governança. O presente trabalho, corroborando com os demais, utilizará a governança de forma geral, de acordo com os níveis já existentes criados pela B3. Para Rogers et al. (2008) o nível de governança corporativa ou a adesão dessa deve impactar diretamente no nível ou intensidade de seu risco idiossincrático. 


\section{METODOLOGIA}

Para atender ao objetivo de pesquisa de verificar as características do risco idiossincráticos nos setores econômicos e de governança, o estudo qualifica-se quanto aos objetivos como descritivos, quanto aos procedimentos como documental e quanto ao tratamento dos dados como quantitativo. A amostra da pesquisa considera todas as ações das empresas negociadas na B3 entre o período de janeiro de 2011 e dezembro de 2015, o período justifica-se por serem os cinco anos mais recentes do fechamento do balanço anual no período de realização do estudo. Todos os dados necessários para a realização da pesquisa foram coletados por meio da base de dados da Thomson ${ }^{\circledR}$.

Os setores analisados de acordo com a Brasil, Bolsa, Balcão estão apresentados na Tabela 1 , no qual obtiveram-se dez setores econômicos conforme próprio mercado de capitais brasileiros, e ainda se apresentam no Painel B da Tabela 1 os níveis de governança corporativa também classificados pela própria bolsa devido características específicas mencionadas na revisão de literatura supra desenvolvido. Ressalta que o setor de tecnologia da informação e telecomunicação foi agrupado devido ao número reduzido de empresas em cada setor.

Tabela 1 - Amostra da Pesquisa

\section{PAINEL A}

\begin{tabular}{l|l}
\hline Bens Industriais & Petróleo, Gás e Biocombustíveis \\
\hline Consumo Cíclico & Saúde \\
\hline Consumo Não-Cíclico & Tecnologia da Informação (S8) \\
\hline Financeiro e Outros & Telecomunicações (S8) \\
\hline Materiais Básicos & Utilidade Pública \\
\hline PAINEL B & \\
\hline
\end{tabular}

Nível 1 de governança

Nível 2 de governança

Novo Mercado

Fonte: Elaborado pelos Autores

Da amostra selecionada foram excluídas as empresas cujas ações foram negociadas por período menor do que 15 dias mensais para intervalo do estudo e as empresas que não apresentavam dados em todo o período amostral, de acordo com metodologia de Fu (2009) e Mendonça et al. (2012). Complementarmente, e de acordo com as metodologias supracitadas, exclui-se da amostra as empresas cujo Patrimônio Líquido encontravam-se negativo no dia do fechamento do balanço em pelo menos um dos anos do intervalo investigado.

Para obtenção do risco idiossincrático utilizou-se o modelo de 3-Fatores de Fama e French (1993) que emprega para a explicação do retorno dos ativos o prêmio pelo risco (diferença entre o retorno da carteira de mercado e da taxa livre de risco), o retorno de uma carteira Small minus Big(SMB) e o retorno de uma carteira High minus Low (HML). Os dados utilizados no presente estudo foram mensais para o período amostral. O modelo de Fama e French (1993) é expresso pela equação 1:

$$
R_{i t}-R_{f t}=a_{i t}+b_{i t}\left(R_{m t}-R_{f t}\right)+s_{i t} S M B_{t}+h_{i t} H M L_{t}-\varepsilon_{i t}
$$

No qual $i$ indica a empresa e $t$ indica o mês, $R_{i t}$ é o retorno estimado da ação em cada mês, $R_{f}$ é a taxa livre de risco, $R_{m}$ é a taxa de retorno do mercado, $S M B_{t}$ e $H M L_{t}$ representam os retornos mensais das carteiras $S M B$ e $H M L$, e $b_{i t}, s_{i t}$ e $h_{i t}$ são os coeficientes relativos a cada fator. Como proxy da taxa livre de risco para o Brasil foi utilizada a taxa SELIC e como proxy para a carteira de mercado brasileira utilizou-se o índice do Ibovespa (CASTRO-JUNIOR; YOSHINAGA, 2012) 
Para composição das carteiras SMB, calculada como a média dos retornos de carteiras de ações de pequenas empresas menos a média dos retornos de carteiras de ações de empresas grandes, e $H M L$, calculada como a diferença de retornos de carteiras formadas por empresas com altos e baixos índices book-to-market, foi utilizada a metodologia proposta pelos autores do modelo. A coleta de dados foi feita na base de dados da Thomson®, no qual foi coletado o preço de fechamento das ações diários, o patrimônio líquido, a quantidade de ações, os pontos do Ibovespa e a taxa SELIC.

A formação das carteiras SMB e HML ocorreu em três passos: primeiramente calculouse o retorno das ações para cada período (valor da ação atual dividido pelo valor da ação do período anterior menos um), o índice book-to-market (Valor contábil dividido pelo valor de mercado) e o valor de mercado (quantidade de ações multiplicadas pelo preço do fechamento da ação) para cada empresa nos cinco anos; após foram ordenadas anualmente as empresas de acordo com o valor de mercado (do menor para o maior), e separou-se as empresas da amostra em dois grupos: o grupo antes da mediana, denominado de Smalle o segundo grupo após a mediana, chamado de Big.

Posteriormente ordenou-se cada grupo separadamente de acordo com o valor do book-tomarket, classificando as empresas ordenadas em três carteiras distintas: as empresas abaixo do $30^{\circ}$ percentil é denominada Low, as empresasacima do $70^{\circ}$ percentil denominam-seHigh e as empresas entre o $30^{\circ}$ e o $70^{\circ}$ percentil são chamadas de Neutral, esse processo foi repetido para os dois grupos SmalleBig. A formação das carteiras de forma sucinta é apresentada na tabela 2.

Tabela 2 - Formação das carteiras para os fatores SMB e HML

\begin{tabular}{c|c|c|c}
\hline \multirow{2}{*}{ Valor de mercado } & Small & Big & \multirow{2}{*}{ Valor de Mercado } \\
\hline \multirow{3}{*}{ Book-to-Market } & Antes da mediana & Depois da mediana & \multirow{2}{*}{ Book-to-Market } \\
\cline { 2 - 3 } & $30^{\circ}$ Growth & $30^{\circ}$ Growth & Neutral \\
\cline { 2 - 3 } & Neutral & $70^{\circ}$ Value & \\
\hline
\end{tabular}

Fonte: Adaptado de Rogers \& Securato (2009)

Para verificar as características do risco idiossincráticos nos setores econômicos e de governança pelo modelo de 3-Fatores apresentado acima, será feita a análise do risco de acordo com os setores de forma comparativa, bem como os níveis de governanças, e posteriormente feita a verificada a relação de acordo com os testes de médias. A regressão do modelo proposto foi feita por meio do software SPSS 21.0, bem como os testes de médias e a regressão realizada como análise de sensibilidade.

\section{ANÁLISE DOS RESULTADOS}

A análise dos resultados será apresentada em duas etapas, primeiramente será explanado os resultados da análise quanto ao risco idiossincrático determinado por cada setor de atividade econômica e posteriormente será exposto os resultados obtidos referentes aos níveis de governança corporativa. A amostra de pesquisa compõe todas as empresas com dados disponíveis listadas na B3, sendo essa compreendida de 356 (70\%) empresas de um total de 507 (100\%), inferindo grande relevância na área de pesquisa.

\subsection{Análise do risco idiossincrático de acordo com o setor econômico}

A Tabela 3 explana as estatísticas descritivas, estas de média, desvio-padrão, mínimo e máximo, dos nove setores de atividade econômica conforme metodologia e destacados no estudo. Na tabela sub exposta as estatísticas se referem à todas empresas do setor de atuação de Bens-Industrias, Consumo Cíclico, Consumo Não-Cíclico, Financeiro e Outros, Materiais 
Básicos, Petróleo, Gás e Biocombustível, Saúde, Tecnologia e Telecomunicação e Utilidade Pública, estes para todos os cinco anos de pesquisa.

Tabela 3 - Estatística descritiva geral dos setores de atividade econômica da B3

\begin{tabular}{c|c|c|c|c|c|c|c|c|c}
\hline & BI & CC & CNC & FNO & MB & PGC & SDE & TEC & UPB \\
\hline$\Sigma$ & 0.30680 & 0.08453 & 0.08477 & 0.11215 & 0.03259 & 0.03439 & 0.08626 & 0.10203 & 0.07592 \\
\hline $\bar{X}$ & 0.14724 & 0.10011 & 0.09447 & 0.11530 & 0.08868 & 0.06614 & 0.09474 & 0.13085 & 0.09750 \\
\hline Máx & 4.01468 & 0.41206 & 0.36908 & 0.63543 & 0.19306 & 0.15421 & 0.37434 & 0.34874 & 0.42038 \\
\hline Min & 0.00056 & 0.00062 & 0.01003 & 0.00062 & 0.03851 & 0.02735 & 0.01685 & 0.03851 & 0.02281 \\
\hline
\end{tabular}

$\sigma=$ desvio-padrão; $\overline{\mathrm{X}}=$ média amostral; Máx = máximo; Min = Mínimo.

Fonte: Dados da Pesquisa

Encontra-se de acordo com os resultados obtidos que o setor de atuação com menor risco idiossincrático de acordo com sua média é o setor de Petróleo, Gás e Biocombustível, esse também possui um dos menores desvios-padrão, indicando que os dados não possuem grande variabilidade, e sendo constantemente menores que os demais setores analisados. $\mathrm{O}$ setor de Materiais Básicos é o setor respectivamente posterior, possuindo a segunda menor média para o risco idiossincrático do estudo e apresentando o menor desvio padrão entre os setores.

Ao ser analisado o outro extremo dos dados tem se o setor de Bens Industriais como o que contém a maior média entre os dados e o maior desvio-padrão, porém em analise particular deste setor foi desconsiderado uma empresa caracterizada comooutlier, e deste modo tem-se novos valores para o setor BI que o representam mais adequadamente, originando $\sigma=0,12655, \bar{X}=0,12069$, Máx $=0,70459$ e Mín $=0,00056$, que o retira da posição de setor com maior risco idiossincrático, porém ainda o qualifica como o segundo setor com maior média para o risco em estudo, juntamente com o setor de tecnologia e telecomunicação que possui o maior risco idiossincrático da amostra. O setor BI possui mesmo com a exclusão do outlier o maior desvio-padrão dos setores, indicando uma inconsistência entre as empresas do setor e expressando uma grande variabilidade entre os seus valores, o setor TEC mesmo tendo o maior risco, tem seus dados um pouco mais semelhantes sendo apenas o terceiro setor com maior desvio-padrão.

O setor BI ainda possui o maior valor de máximo entre os setores, tendo este a diferença de 0,55 para o menor valor de máximo pertencente ao setor de Petróleo, Gás e Biocombustível. Já os valores mínimos de cada setor são semelhantes, destacando apenas os setores BI, CC e FNO que possui os mais baixos, realmente baixos, valores para o mínimo setorial. Tais diferenças setoriais ocorrem pois conforme Silva et al. (2014) os diferentes setores de atuação das empresas as levam a diferentes posicionamentos e diferentes características. A tabela 4 apresenta o teste de médias entre os setores estudados.

Tabela 4- Teste de médias para os setores econômicos de acordo com o risco idiossincrático

\begin{tabular}{|c|c|c|c|c|c|}
\hline \multicolumn{6}{|c|}{ Teste de Médias } \\
\hline Dados & Grupo & Qnt. & Média & $\mathbf{T}$ & Sig. \\
\hline \multirow{2}{*}{ R_IDIO } & 1 & 42 & 0,1472 & \multirow{2}{*}{1,049} & \multirow{2}{*}{0,296} \\
\hline & 2 & 68 & 0,1180 & & \\
\hline \multirow{2}{*}{ R_IDIO } & 1 & 42 & 0,1472 & \multirow{2}{*}{1,140} & \multirow{2}{*}{0,259} \\
\hline & 3 & 16 & 0,0884 & & \\
\hline \multirow{2}{*}{ R_IDIO } & 1 & 42 & 0,1472 & \multirow{2}{*}{1,367} & \multirow{2}{*}{0,178} \\
\hline & 4 & 98 & 0,1034 & & \\
\hline \multirow{2}{*}{ R_IDIO } & 1 & 42 & 0,1472 & \multirow{2}{*}{0,463} & \multirow{2}{*}{0,645} \\
\hline & 5 & 28 & 0,1283 & & \\
\hline \multirow{2}{*}{ R_IDIO } & 1 & 42 & 0,1472 & \multirow{2}{*}{0,995} & \multirow{2}{*}{0,325} \\
\hline & 6 & 7 & 0,0710 & & \\
\hline \multirow{2}{*}{ R_IDIO } & 1 & 42 & 0,1472 & \multirow{2}{*}{0,842} & \multirow{2}{*}{0,404} \\
\hline & 7 & 9 & 0,0901 & & \\
\hline R_IDIO & 1 & 42 & 0,1472 & $-0,719$ & 0,475 \\
\hline
\end{tabular}


Ganz, Bizatto e Kroenke (2018)

Risco Idiossincrático Determinado por

Características Setoriais e de Governança

\begin{tabular}{|c|c|c|c|c|c|}
\hline & 8 & 11 & 0,1939 & & \\
\hline \multirow{2}{*}{ R_IDIO } & 1 & 42 & 0,1472 & \multirow{2}{*}{1,649} & \multirow{2}{*}{0,105} \\
\hline & 9 & 43 & 0,0921 & & \\
\hline \multirow{2}{*}{ R_IDIO } & 2 & 68 & 0,1180 & \multirow{2}{*}{1,234} & \multirow{2}{*}{0,221} \\
\hline & 3 & 16 & 0,0884 & & \\
\hline \multirow{2}{*}{ R_IDIO } & 2 & 68 & 0,1180 & \multirow{2}{*}{1,084} & \multirow{2}{*}{0,280} \\
\hline & 4 & 98 & 0,1034 & & \\
\hline \multirow{2}{*}{ R_IDIO } & 2 & 68 & 0,1180 & \multirow{2}{*}{$-0,501$} & \multirow{2}{*}{0,618} \\
\hline & 5 & 28 & 0,1283 & & \\
\hline \multirow{2}{*}{ R_IDIO } & 2 & 68 & 0,1180 & \multirow{2}{*}{2,975} & \multirow{2}{*}{$0,008 *$} \\
\hline & 6 & 7 & 0,0710 & & \\
\hline \multirow{2}{*}{ R_IDIO } & 2 & 68 & 0,1180 & \multirow{2}{*}{0,912} & \multirow{2}{*}{0,365} \\
\hline & 7 & 9 & 0,0901 & & \\
\hline \multirow{2}{*}{ R_IDIO } & 2 & 68 & 0,1180 & -1642 & 0128 \\
\hline & 8 & 11 & 0,1939 & $-1,042$ & 0,128 \\
\hline & 2 & 68 & 0,1180 & & \\
\hline R_1DIO & 9 & 43 & 0,0921 & 1,531 & 0,129 \\
\hline R IDIO & 3 & 16 & 0,0884 & 0688 & 0403 \\
\hline R_DOIU & 4 & 98 & 0,1034 & $-0,088$ & 0,493 \\
\hline P IDIO & 3 & 16 & 0,0884 & 1410 & 0166 \\
\hline R_IDIO & 5 & 28 & 0,1283 & $-1,410$ & 0,166 \\
\hline R IDIO & 3 & 16 & 0,0884 & 0596 & 0.558 \\
\hline R_DOIO & 6 & 7 & 0,0710 & 0,596 & 0,558 \\
\hline R IDIO & 3 & 16 & 0,0884 & 0056 & 0.056 \\
\hline R_IDIO & 7 & 9 & 0,0901 & $-0,056$ & 0,956 \\
\hline R IDIO & 3 & 16 & 0,0884 & -2 172 & $0048 * *$ \\
\hline K_DOIU & 8 & 11 & 0,1939 & $-2,1 / 2$ & \\
\hline R IDIO & 3 & 16 & 0,0736 & & \\
\hline R_IDIO & 9 & 98 & 0,1034 & $-0,156$ & 0,877 \\
\hline R IDIO & 4 & 98 & 0,1034 & $-1,349$ & 0180 \\
\hline R_IDIO & 5 & 28 & 0,1283 & & 0,180 \\
\hline R IDIO & 4 & 98 & 0,1034 & 1,034 & 0304 \\
\hline R_DOIO & 6 & 7 & 0,0710 & & 0,304 \\
\hline R IDIO & 4 & 98 & 0,1034 & 0,476 & \\
\hline & 7 & 9 & 0,0901 & & 0,635 \\
\hline P IDIO & 4 & 98 & 0,1034 & 1070 & $0074 * * *$ \\
\hline R_IDIO & 8 & 11 & 0,1939 & $-1,919$ & $0,0 / 4 \cdots$ \\
\hline R IDIO & 4 & 98 & 0,1034 & 0751 & 0454 \\
\hline K_IDIOU & 9 & 43 & 0,0921 & $0, / 31$ & 0,434 \\
\hline R IDIO & 5 & 28 & 0,1283 & 2618 & $0014 * *$ \\
\hline R_DOIU & 6 & 7 & 0,0710 & & \\
\hline R IDIO & 5 & 28 & 0,1283 & 1094 & 0281 \\
\hline R_IDIO & 7 & 9 & 0,0901 & 1,094 & 0,281 \\
\hline R IDIO & 5 & 28 & 0,1283 & -1348 & 0200 \\
\hline & 8 & 11 & 0,1939 & $-1,340$ & 0,200 \\
\hline R IDIO & 5 & 28 & 0,1283 & 1665 & 0101 \\
\hline K_IDIO & 9 & 43 & 0,0921 & 1,00J & \\
\hline & 6 & 7 & 0,0710 & -0806 & 0436 \\
\hline R_IDIO & 7 & 9 & 0,0901 & $-0,806$ & 0,436 \\
\hline P IDIO & 6 & 7 & 0,0710 & 2648 & 0022 ** \\
\hline K_IDIO & 8 & 11 & 0,1939 & $-2,048$ & $0,0<2 \cdots$ \\
\hline R IDIO & 6 & 7 & 0,0710 & -0.656 & 0.515 \\
\hline K_IDIO & 9 & 43 & 0,0921 & $-0,656$ & 0,ग15 \\
\hline R IDIO & 7 & 9 & 0,0901 & -2 101 & $0054 * * *$ \\
\hline K_WIO & 8 & 11 & 0,1939 & $-2,101$ & 0,034 \\
\hline
\end{tabular}


Ganz, Bizatto e Kroenke (2018)

Risco Idiossincrático Determinado por

Características Setoriais e de Governança

\begin{tabular}{|c|c|c|c|c|c|}
\hline \multirow{2}{*}{ R_IDIO } & 7 & 9 & 0,0901 & \multirow{2}{*}{$-0,070$} & \multirow{2}{*}{0,944} \\
\hline & 9 & 43 & 0,0921 & & \\
\hline \multirow{2}{*}{ R_IDIO } & 8 & 11 & 0,1939 & \multirow{2}{*}{2,179} & \multirow{2}{*}{$0,051 * * *$} \\
\hline & 9 & 43 & 0,0921 & & \\
\hline \multicolumn{6}{|c|}{ *. A relação é significativa no nível 0,01 (2 extremidades). } \\
\hline \multicolumn{6}{|c|}{ **. A relação é significativa no nível 0,05 (2 extremidades). } \\
\hline \multicolumn{6}{|c|}{ ***. A relação é significativa no nível 0,10 (2 extremidades). } \\
\hline \multicolumn{6}{|c|}{$\begin{array}{l}\text { Legenda:0: Mercado Tradicional; 1: Nível } 1 \text { de Governança corporativa B3; 2: Nível } 2 \text { de Governança } \\
\text { corporativa B3; 3: Novo Mercado de Governança corporativa B3; Qnt.: Quantidade de observaçôes em cada } \\
\text { categoria. }\end{array}$} \\
\hline
\end{tabular}

Fonte: Dados da Pesquisa

De acordo com o teste de médias sete setores quando comparados de forma binária apresentaram diferença estatisticamente significativa. $O$ setor 8 , referente ao setor de tecnologia e telecomunicação, foi o que apresentou o risco idiossincrático mais díspar quando comparados com os outros setores, confirmando os resultados da estatística descritiva. O setor de tecnologia possui diferença de média do risco idiossincrático com os setores 3 - Consumo Não-Cíclico, 4 - Financeiro e Outros, 6 - Petróleo, Gás e Biocombustíveis, 7 - Saúde e 9 Utilidade Pública.

O setor 6 (Petróleo, Gás e Biocombustíveis) apresentou diferença estatística com os setores 2 - Consumo Cíclico e 5 - Materiais Básicos. Ressalta-se que os setores que apresentaram diferença de média quando comparado com os demais foram os setores que apresentaram riscos extremos, ou seja, o setor com maior risco idiossincrático e o setor com o menor risco. O setor de PGC é o que apresentou os menores valores de risco idiossincrático para o período e o setor TEC é o que apresentou menor valor do risco idiossincrático, comprovando desta forma a diferenciação do risco especifico das empresas destes setores.

Os resultados encontrados complementam o estudo de Silva, Paulo e Silva (2016) que encontra relação entre as características setoriais e o conservadorismo, ao encontram a relação dos setores econômicos com o risco idiossincráticos das organizações. Ressalta-se que a significância e diferença encontrada, mesmo que necessitando de maiores investigações sobre a temática, pode indicar uma influência do setor no risco idiossincrático, isto por que o setor de tecnologia e telecomunicação foi o setor com risco idiossincrático mais díspar dos demais, sendo este o setor de apenas a terceira maior média para este risco, enquanto o primeiro e segundo com maior média não se destacaram, reduzindo a possibilidade dessas diferenças ocorrerem por conta do tamanho.

Ainda, um análise mais conivente com os resultados é que o setor de tecnologia e telecomunicação é um setor de empresas que estão mais expostas aos avanços da sociedade, tecnologicamente e socialmente, sendo que para este setor a competitividade é demasiada, e que empresas desse ramo precisam estar sempre se reinventando para continuar ativa e competitiva no mercado, o que é condizente com maiores risco e maior risco idiossincrático. Dito isto, os resultados corroboram também com a afirmação de Assaf Neto (2007) de que por possuir características e retornos diferentes, os setores econômicos possuem diferentes riscos incumbidos a estes.

\subsection{Análise da governança corporativa}

De forma semelhante a tabela 5 apresenta os valores do risco idiossincrático para os três diferentes níveis de governança corporativa da Bolsa de Valores de São Paulo, compreendendo em conjunto 130 empresas das 356 da amostra que estão listadas nas classificações de governança mencionadas.

Tabela 5- Estatísticas descritivas dos segmentos de Governança Corporativa da B3

\begin{tabular}{l|l|l} 
N1 & N2 & NM \\
\hline
\end{tabular}


Ganz, Bizatto e Kroenke (2018)

Risco Idiossincrático Determinado por

Características Setoriais e de Governança

\begin{tabular}{c|c|c|c}
\hline$\sigma$ & 0.10276 & 0.11481 & 0.08522 \\
\hline $\bar{X}$ & 0.10227 & 0.12578 & 0.09803 \\
\hline Máx & 0.46165 & 0.67635 & 0.63543 \\
\hline Min & 0.00056 & 0.03605 & 0.00056 \\
\hline$\sigma$
\end{tabular}

$\sigma=$ desvio-padrão; $\bar{X}=$ média amostral; Máx = máximo; Min = Mínimo;

Fonte: Dados da Pesquisa

De acordo com a tabela supra exposta o setor com menor média amostral é o nível mais rigoroso de governança corporativa com média de 0,09803, sendo o que apresenta também o menor valor para o desvio-padrão, indicando baixo valor do risco idiossincrático e constância entre as empresas do grupo no mantimento dos baixos valores. Tais resultados corroboram com os achados de Monte et al. (2010) que encontraram em seu estudo que as empresas listadas no Novo mercado apresentaram menor volatilidade dos que as empresas dos demais níveis de governança. Além de ir ao encontro da afirmação de Rogers et al. (2008) que quanto maior o nível de governança à impacto no nível e intensidade do risco idiossincrático, indicando que quando maior o nível de governança menor o risco idiossincrático. Ainda segundo Leary e Michael (2010) a associação ocorre por que as práticas de boa governança reduzem a assimetria de informação e as idealizações distintas por parte dos gestores, impactando no risco idiossincrático.

Já o Nível 2 apresenta surpreendentemente os maiores valores em todas as estatísticas descritivas, podendo ser inferido como o pior cenário de investimento entre os três níveis. $\mathrm{O}$ que se torna contraditório às afirmações apresentadas com os autores supra apresentados que em suma afirmam que quanto maior o Nível de Governança menor o risco, porém no presente estudo o Nível 1 supera o Nível 2 na qualidade da variável em estudo. O Nível 1 de governança corporativa contem valores parecidos com o do Novo Mercado apresentando valores levemente maiores na média e desvio-padrão, valor igual quando se refere ao mínimo e menor quanto ao máximo. Discordando de Silva et al. (2015) que afirmam também que os níveis 1 e 2 de governança corporativa da bolsa não devem possuir grandes diferenças. Para confirmação dos resultados a tabela 6 apresenta o teste de médias realizado de forma binária para o risco idiossincrático dos diferentes níveis de governança corporativa.

Tabela 6 - Teste de Médias Governança Corporativa

\begin{tabular}{|c|c|c|c|c|c|}
\hline \multicolumn{6}{|c|}{ Teste de médias } \\
\hline Dados & Grupo & Qnt. & Média & $\mathbf{T}$ & Sig. \\
\hline \multirow{2}{*}{ R_IDIO } & 0 & 226 & 0,1237 & \multirow{2}{*}{0,772} & \multirow{2}{*}{0,441} \\
\hline & 1 & 28 & 0,1023 & & \\
\hline \multirow{2}{*}{ R_IDIO } & 0 & 226 & 0,1237 & \multirow{2}{*}{$-0,051$} & \multirow{2}{*}{0,960} \\
\hline & 2 & 13 & 0,1258 & & \\
\hline \multirow{2}{*}{ R_IDIO } & 0 & 226 & 0,1237 & \multirow{2}{*}{2,0165} & \multirow{2}{*}{$0,031 * *$} \\
\hline & 3 & 89 & 0,0980 & & \\
\hline \multirow{2}{*}{ R_IDIO } & 1 & 28 & 0,1023 & \multirow{2}{*}{$-0,754$} & \multirow{2}{*}{0,456} \\
\hline & 2 & 13 & 0,1258 & & \\
\hline \multirow{2}{*}{ R_IDIO } & 1 & 28 & 0,1023 & \multirow{2}{*}{0,270} & \multirow{2}{*}{0,788} \\
\hline & 3 & 89 & 0,0980 & & \\
\hline \multirow{2}{*}{ R_IDIO } & 2 & 13 & 0,1258 & \multirow{2}{*}{1,306} & \multirow{2}{*}{0,195} \\
\hline & 3 & 89 & 0,0980 & & \\
\hline
\end{tabular}

*. A correlação é significativa no nível 0,01 (2 extremidades). **. A correlação é significativa no nível 0,05 (2 extremidades).

Legenda:0 Mercado Tradicional; 1 Nível 1 de Governança corporativa B3; 2 Nível 2 de Governança corporativa B3; 3 Novo Mercado de Governança corporativa B3; Qnt. Quantidade de observações em cada categoria.

Fonte: Dados da Pesquisa

De acordo com o teste de médias há diferença estatisticamente significativa somente entre o nível tradicional de governança (0) e o Novo Mercado (3), sendo está à nível de 5\%.

Revista de Gestão, Finanças e Contabilidade - v. 8, n. 3, p. 4-19, set./dez. 2018 ISSN 2238-5320, UNEB, Salvador/BA 
Logo comprova-se a menor média do risco idiossincrático para as empresas pertencentes ao Novo Mercado, sendo esta corroborativa com a análise descritiva. Porém não se comprova a diferença de médias entre as empresas do Nível 2 e os demais níveis de governança, necessitando de mais estudos que estudem as características particulares deste nível de governança e a sua influência no risco idiossincrático.

Além das estatísticas descritivas e dos testes de médias, realizou-se para averiguar a relação da governança corporativa e do setor econômico no risco idiossincrático uma análise de regressão, os resultados desta estão expostos na tabela 7.

Tabela 7 - Regressão Linear

\begin{tabular}{c|c|c|c|c|c|c}
\hline \hline $\begin{array}{c}\text { Variável } \\
\text { dependente }\end{array}$ & $\begin{array}{c}\text { Variável } \\
\text { independente }\end{array}$ & Beta & t-statistic & Sig. & \multirow{2}{*}{$\mathbf{R}^{2}$} & \multirow{2}{*}{$\mathbf{R}^{2}$ Ajust } \\
\cline { 2 - 5 } & Const. & 0,132 & 9,503 & 0,000 & & \multirow{2}{*}{0,095} \\
\cline { 2 - 5 } R_IDIO & $\begin{array}{c}\text { Setor } \\
\text { Econômico }\end{array}$ & $-0,002$ & $-0,782$ & 0,435 & 0,009 \\
\cline { 2 - 5 } & $\begin{array}{c}\text { Nível de } \\
\text { Governança }\end{array}$ & $-0,009$ & $-1,719$ & $0,087 * * *$ & & \\
\hline
\end{tabular}

*. A relação é significativa no nível 0,01 (2 extremidades).

**. Arelação é significativa no nível 0,05 (2 extremidades).

***. A relação é significativa no nível 0,10 ( 2 extremidades).

Legenda: CET - Nível de ceticismo; E- Nível de estresse;

Fonte: Dados da Pesquisa

De acordo com os resultados encontrados o nível de governança corporativa influência de forma inversa o risco idiossincrático, indicando que quanto maior o nível de governança menor o risco idiossincrático da empresa. O achado de que a governança corporativa influencia o risco idiossincrático é corroborativo com os estudos de Durnev, Morck e Yeung (2004),Ferreira e Laux (2007), Nguyen(2011), Wu(2013) eAbu-Ghunmia, Bino e Tayeh (2015) que encontram a mesma relação.

O setor econômico não apresenta coeficiente significativo na análise da regressão o que indica que não se pode afirmar que determinado setor econômico determina um maior ou menor risco idiossincrático para as empresas. Porém, maiores pesquisas devem analisar os dois setores destacados que apresentaram diferença de médias quando comparados aos demais setores, pois há fortes evidencias que estes setores, tecnologia e telecomunicação e Petróleo, Gás e Biocombustível, possuem alguma influência particular que afeta o risco idiossincrático.

\section{CONSIDERAÇÕES FINAIS}

A presente pesquisa objetivou analisar o risco idiossincrático nos diferentes setores econômicos e níveis de governança. Para alcançar o objetivo utilizou-se o modelo de três fatores de Fama e French (1993) para estimação do risco idiossincrático, e teste de médias e regressão para analisar e associar a influência setorial ou por nível de governança corporativa com o risco idiossincrático.

Para a análise dos resultados, após estimar o risco idiossincrático para as 356 empresas que compreenderam a amostra e das 1780 regressões rodadas para estimar tal risco por ano e por empresa, o conjunto amostral foi subdividido entre nove setores de atividade econômica, estando conjuntos para analise o setor de Tecnologia e o setor de Telecomunicação, e os três níveis de governança corporativa da bolsa de valores de São Paulo. Conclui-se de acordo com o analisado que o setor de Petróleo, Gás e Biocombustível é o setor que apresenta de forma constanteo menor risco idiossincrático, diante de tal resultado pode ser inferido que este é decorrente do fato do setor PGB ser um dos setores com maiores regulações e delimitações. 
Após este, o setor de Materiais Básicos é o segundo setor com menor risco idiossincrático, é o que possui maior consistência dos resultados. Após esses destaca-se os setores de Bens Industriais e de Tecnologia e Telecomunicação que apresentam as maiores médias para o risco em estudo, oferecendo assim maior risco volátil e diversificado para as carteiras que possuírem ativos/ações de tais empresas. Quanto aos níveis de governança corporativa tem se com os maiores valores de risco idiossincrático as empresas pertencentes ao Nível 2, sendo um resultado inesperado na pesquisa.

Já o Novo Mercado, classificação mais rigorosa de governança, possui os menores valores do risco idiossincrático bem como o menor desvio-padrão, indicando e corroborando com a literatura que o maior nível de governança corporativa produz uma menor intensidade do risco idiossincrático. E inferindo que investidores que possuem seus portfolios com ações de empresas com alto nível de governança possuem menor risco idiossincrático precificado em seus ativos e menor risco quanto às volatilidades particulares das empresas, estão mais fortemente incumbidos à risco mercadológicos e econômicos do que específicos. Conclui-se de acordo com os achados da pesquisa que a governança corporativa influencia o risco idiossincrático, e que as características setoriais necessitam de maiores investigações para afirmar a influência ou não influencia no risco específico das empresas.

Os resultados da pesquisa contribuem para os usuários externos da informação contábil, usuários da contabilidade financeiras e pesquisadores e profissionais do mercado de capitais, ao identificar quais são as características setoriais e de governança do risco idiossincrático no cenário brasileiro, encontrando que alguns setores e o maior nível de governança corporativa de acordo com bolsa de valores de São Paulo possuem os menores risco do mercado de capitais brasileiro. O estudo apresenta diferencial ao analisar a temática do risco idiossincrático no Brasil, por ser tema de pesquisa pouco investigado na literatura nacional, além de fazê-la com a maior amostra possível disponível e por fim por relaciona-la com os setores de atividade econômica e por segmento de governança os quais não foram encontradas, nem meramente semelhantes, na literatura. Contribuindo assim, ao ampliar e consolidar características sobre o risco idiossincrático.

Pesquisas futuras podem ser feitas ao utilizar outras metodologias para estimação do risco idiossincrático, como series temporais, modelo 1-Fator, modelo de 5-Fatores, entre outras metodologias presente na literatura. Ainda poder-se-á realizar a pesquisa em um período amostral maior para confirmação dos resultados encontrados. Demais pesquisas poderiam procurar comparar se o mesmo resultado se repete em países com caraterísticas semelhantes ao Brasil, poderiam ainda a amostra de pesquisa ser separada de acordo com outras características para analisar outros agrupamentos semelhantes.

\section{REFERÊNCIAS}

ABU-GHUNMI, D.; BINO, A.; TAYEH, M. Idiosyncratic Risk and Corporate Governance: Evidence from Jordan. Emerging Markets Finance and Trade, 51(sup4), S40-S50. 2015.

ALEXANDRE, M.; LIMA, G. T.; CANUTO, O. Determinantes das decisões locacionais da atividade financeira. Nova Economia, v. 16, n 2, 243-263. 2006.

ASSAF NETO, A. Finanças corporativas e valor. 3. ed. São Paulo: Atlas.2007.

BALI, T. G.; CAKICI, N.; LEVY, H. A model-independent measure of aggregate idiosyncratic risk. Journal of Empirical Finance, v. 15, n. 5, p. 878-896. 2008.

BESARRIA, C. N.; PAULA, Â. A.; ARAÚJO, B. S.; ALVES, J. N.; ALMEIDA, F. F.; MONTEIRO, V. S. A qualidade das informações prestadas pelas empresas reduz os riscos de 
investimento? uma análise empírica para os diferentes níveis de governança corporativa das empresas brasileiras. Race: revista de administração, contabilidade e economia, v. 14, n. 1, p. 11-38. 2015.

B3. Critério de Classificação. Recuperado em 2 novembro, 2016, de http://www.bmfbovespa.com.br/pt_br/produtos/listados-a-vista-e-derivativos/rendavariavel/acoes/criterio-de-classificacao/.

B3. Segmentos de listagem. Recuperado em 2 novembro, 2016, de http://www.bmfbovespa.com.br/pt br/listagem/acoes/segmentos-de-listagem/sobresegmentos-de-listagem/.

CASTRO-JUNIOR, F. H. F.; YOSHINAGA, C. E. Coassimetria, cocurtose e as taxas de retorno das ações: uma análise com dados em painel. Revista de Administração Mackenzie, v. 13, n. 1, p. 110. 2012.

CAZZARI, R. B.; FÁVERO, L. P. L.; TAKAMATSU, R. T. Governança Corporativa e Beta de Empresas Listadas na BM\&FBOVESPA. Revista Catarinense da Ciência Contábil, v. 14, n. 43, p. 51-62. 2015.

COSTA, H. C.; MAZZEU, J. H. G.; COSTA JR, N. C. A. O Comportamento dos Componentes da Volatilidade das Ações no Brasil/(The Behaviour of Volatility Components of Brazilian Stocks). Revista Brasileira de Financas, v. 14, n. 2, p. 225.2016.

DURNEV, A.; MORCK, R.; YEUNG, B. Value-enhancing capital budgeting and firm-specific stock return variation. The Journal of Finance, v. 59, n. 1, p. 65-105. 2004.

FAMA, E. F.; FRENCH, K. R. Common risk factors in the returns on stocks and bonds. Journal of financial economics, v. 33, n. 1, p. 3-56. 1993.

FÁVERO, L. P.; BELFIORE, P.; SILVA, F. D.; CHAN, B. L. Análise de dados: modelagem multivariada para tomada de decisões.2009.

FERREIRA, M. A.; LAUX, P. A. Corporate governance, idiosyncratic risk, and information flow. The Journal of Finance, v. 62, n. 2, p. 951-989. 2007.

FU, F.Idiosyncratic risk and the cross-section of expected stock returns. Journal of Financial Economics, v. 91, n. 1, p. 24-37. 2007.

GALDI, F. C.; SECURATO, J. R. Does Idiosyncratic Risk Matter in the Brazilian Capital Market?. Brazilian Review of Finance, v. 5, n. 1, p. 41-58. 2007.

LEARY, M. T.; MICHAL, R. The pecking order, debt capacity, and information asymmetry.Journal of Financial Economics. v. 95, n. 3, p. 332-355. 2010.

LEE, B. S.; LI, L. The Idiosyncratic Risk-Return Relation: A Quantile Regression Approach Based on the Prospect Theory. Journal of Behavioral Finance, v. 17, n. 2, p. 124-143. 2016.

LINTNER, J. The valuation of risk assets and the selection of risky investments in stock portfolios and capital budgets. The review of economics and statistics, p. 13-37. 1995.

MARKOWITZ, H. Portfolio selection. The journal of finance, v. 7, n. 1, p. 77-91.1952.

MATUCHESKI, S.; CLEMENTE, A.; SANDRINI, J. C. Governança corporativa e volatilidade das ações negociadas na Bovespa na crise financeira de 2008. Revista Brasileira de Estratégia, v. 2, n. 2, p. 171-183. 2009. 


\section{Risco Idiossincrático Determinado por \\ Características Setoriais e de Governança}

MENDONÇA, F. P.; KLOTZLE, M. C.; PINTO, A. C. F.; MONTEZANO, R. M. S. A Relação entre Risco Idiossincrático e Retorno no Mercado Acionário Brasileiro/The Relationship between Idiosyncratic Risk and Returns in the Brazilian Stock Market. Revista Contabilidade \& Finanças, v. 23, n. 60, p. 246. 2012.

MONTE, P. A.; REZENDE, I. C. C.; TEIXEIRA, G. S.; BESARRIA, C. N. Existe relação entre Governança Corporativa e volatilidade? Um estudo a partir da formação de carteiras.

Contabilidade Vista \& Revista, v. 21, n. 2, p. 15-44.2010.

NGUYEN, P. Corporate governance and risk-taking: Evidence from Japanese firms. PacificBasin Finance Journal, v. 19, n. 3, p. 278-297. 2011.

RIGHI, M. B.; SCHLENDER, S. G.; CERETTA, P. S. Comovimentos entre Setores Econômicos Brasileiros: uma abordagem não linear. Revista de Ciências da Administração, v. 16, n. 38, p. 63. 2014.

ROGERS, P.; MACHADO FILHO, C. A. P.; SECURATO, J. R. Governança corporativa, risco operacional e comportamento e estrutura a termo da volatilidade no mercado de capitais brasileiro. ENCONTRO NACIONAL DE PESQUISA EM ADMINISTRAÇÃO, p. 32. 2008.

ROGERS, P.; RIBEIRO, K. C. S.; SOUSA, A. F. Impactos de fatores macroeconômicos nas melhores práticas de governança corporativa no Brasil. Revista de Administração, v. 42, n. 3, p. 265-279.2007.

ROLL, R. "R2". Journal of Finance. v. 43, n. 3, p. 541-566.1988.

RUBIN, A.; SMITH, D.R. "Comparing Different Explanations of the Volatility Trend." Journal of Banking and Finance. 35, n. 6: 1581-1597. 2011.

SHARPE, W. F. Capital asset prices: A theory of market equilibrium under conditions of risk. The Journal of Finance, v. 19, n. 3, p. 425-442. 1964.

SILVA, A. R. P.; PAULO, E.; SILVA, J. D. G. Efeitos da adoção das IFRS no Conservadorismo Contábil: uma análise sob a ótica dos Setores Econômicos-Accounting Conservatism in Brazilian Companies Following the adoption of IFRS Under the arrangement of the Economy Sectors. Amazônia, Organizações e Sustentabilidade, v. 5, n. 1, p. 115131. 2016.

SILVA, P. Z. P.; ARAÚJO, V. R. B. S.; MONTE, P. A. Uma Análise da Pecking Order Theory nos Diferentes Níveis de Governança Corporativa da BM\&FBovespa. IX congresso AnpCont. Curitiba-PR. 2015.

SILVA, S. S.; REIS, R. P.; AMÂNCIO, R. Conceitos atribuídos à sustentabilidade em organizações de diferentes setores. Revista de Ciências da Administração, p. 90-103. 2014.

TONANI, R.; SILVA, R. L. M. Relação entre a divulgação de pagamentos baseados em ações e os níveis de Governança Corporativa da BM\&FBovespa. Enfoque: Reflexão Contábil, v. 33, n. 3, p. 51-66. 2014. 